\title{
Evaluation of respiratory impedance in patients with chronic obstructive pulmonary disease by an impulse oscillation system
}

\author{
SU-GANG GONG ${ }^{1 *}$, WEN-LAN YANG ${ }^{2^{*}}$, WEI ZHENG ${ }^{2}$ and JIN-MING LIU ${ }^{1}$ \\ Departments of ${ }^{1}$ Respiratory Medicine and ${ }^{2}$ Pulmonary Function, Shanghai Pulmonary Hospital, \\ Tongji University School of Medicine, Shanghai 200433, P.R. China
}

Received August 13, 2013; Accepted April 4, 2014

DOI: $10.3892 / \mathrm{mmr} .2014 .2528$

\begin{abstract}
An impulse oscillometry system (IOS) assesses pulmonary resistance and reactance. The present study investigated which IOS measurement is correlated with airflow obstruction, airway conductance and lung volume in chronic obstructive pulmonary disease (COPD). A total of 180 patients with COPD were selected and 95 agreed to follow-up 1 year after the initial tests. IOS measurements [R5, R20, X5 and resonant frequency (Fres)], body plethysmography [forced end-expiratory flow (FEF)75, total lung capacity, residual volume (RV) and total inspiratory resistance (Rtot)] and spirometry [forced expiratory volume in $1 \mathrm{sec}$ (FEV1)] were performed. Pearson's or Spearman's correlation tests were used to determine the correlation between the IOS and other measurements. R5, X5 and Fres were all significantly associated $(\mathrm{P}<0.05)$ with FEV1, FEF75, RV and Rtot. However, R20 was not correlated with these measurements except from FEF75 and Rtot ( $\mathrm{r}$ values were all $<0.25)$. The strongest associations were observed with FEV1 and the reactance measurements X5 ( $\mathrm{r}=0.635)$, Fres $(\mathrm{r}=-0.721)$ and R5 $(\mathrm{r}=-0.496)$; FEF75 with X5 $(\mathrm{r}=0.505)$, Fres $(\mathrm{r}=-0.629)$ and R5 $(\mathrm{r}=-0.468)$; RV with X5 $(\mathrm{r}=-0.485)$, Fres $(r=0.570)$ and R5 ( $r=0.326)$; and Rtot with X5 ( $r=-0.691)$, Fres $(\mathrm{r}=0.632)$ and $\mathrm{R} 5(\mathrm{r}=0.570)$. There was a significant increase in FEV1 and X5 after one year as compared with the RV. The other measurements did not change over the year. The changes in X5, Fres and R5 were significantly correlated with the changes in FEV1 and the correlation coefficients were 0.355 , -0.364 and -0.381 , respectively. Similarly, the changes in X5, Fres and R5 were significantly correlated with the changes in RV and the correlation coefficients were $-0.264,0.287$
\end{abstract}

Correspondence to: Dr Jin-ming Liu, Department of Respiratory Medicine, Shanghai Pulmonary Hospital, Tongji University School of Medicine, 507 Zhengming Road, Yangpu, Shanghai 200433, P.R. China

E-mail: liujm2433@163.com

*Contributed equally

Key words: chronic obstructive pulmonary disease, impulse oscillometry system, spirometry, body plethysmography and 0.318, respectively. In the COPD patients, the IOS reactance measurements were more closely correlated with other pulmonary function measurements rather than with resistance measurements. The IOS reactance measurements, particularly $\mathrm{X} 5$, appear to indicate changes in pulmonary compliance caused by airflow obstruction.

\section{Introduction}

Chronic obstructive pulmonary disease (COPD) is characterized by an airflow obstruction that is partly reversible. This is mainly attributable to the airway narrowing caused by wall remodeling and the wall collapsibility in expiration due to loss of alveolar attachment and elastic recoil of the small airways (1). Spirometry is the 'gold standard' that is used to assess airflow obstruction in COPD patients. Forced expiration is used as part of spirometry in the diagnosis and staging of COPD. This procedure is difficult for patients to perform as it is effort-dependent and can alter the bronchomotor tone. Body plethysmography is an alternative to the pulmonary function testing technique and allows the assessment of airway resistance and conductance. However, it can be technically demanding for patients to perform this test as it requires complex 'panting' maneuvers. Thus, there is a requirement to find easy and physiologically accurate methods to assess pulmonary mechanics in COPD patients.

The forced oscillation technique (FOT) was developed in 1956 (2). FOT measures the impedance of the respiratory system by applying small oscillation pressures on the mouth during a normal breathing forced oscillation technique (3). FOT systems use pseudorandom noise signals to enable simultaneous measurement of respiratory resistance (Rrs) and reactance (Xrs). It has been reported that FOT measurements are associated with traditional lung function measurements in patients with obstructive lung disease $(4,5)$ and it has been shown that in COPD patients, FOT resistance measurements can be used to accurately diagnose mild COPD. However, reactance measurements are better for grading the severity of disease (6). The impulse oscillometry system (IOS) (7) is a type of FOT but has two important differences: (i) Rectangular waveform impulses are used instead of pseudorandom noise signals and (ii) the IOS has a different set of data output. Hellincx et al (8) reported that IOS provides similar but not identical Rrs and reactance measurements when compared with FOT. Thus, this 
study showed that these two techniques may generate different results. Theoretically, the elastic property of the lung is reflected by the low oscillatory frequencies of reactance, while the inertial properties are dominantly reflected in the high oscillatory frequency range of reactance (9). In obstructive lung disease, further increases in Rrs and changes of Xrs to a more negative value at lower oscillatory frequencies have been reported (10). Additionally, it has been reported that the within-breath changes in Xrs5 ( $\Delta \mathrm{Xrs5}$; the difference between expiratory and inspiratory reactance) have been indicated to represent the overall distribution of expiratory flow limitation during tidal breathing (10-12). COPD and asthma studies have shown that IOS measurements are more sensitive than forced expiratory volume in $1 \mathrm{sec}$ (FEV1) for measuring the pulmonary effects of bronchodilator drugs (13-15). Additionally, IOS measurements can also be used to sensitively diagnose obstructive lung disease $(16,17)$. Thus, the understanding of which IOS measurements are correlated with the degree of airflow obstruction (as measured by FEV1) and which measurements are correlated with the degree of hyperinflation (measured by lung volumes) is required. The present study describes the correlation of IOS measurements to other pulmonary function measurements in a large cohort of COPD patients $(n=180)$. A set of patients was followed-up for 1 year and the changes in IOS and spirometry measurements were compared over that period.

\section{Subjects and methods}

Subjects. Patients $(\mathrm{n}=180)$ with COPD were selected for the measurement of pulmonary function (see Table I for demography). All the patients were invited for follow-up 1 year following the initial tests; 95 patients agreed to participate, while the remaining patients were unable to do so. All the patients with COPD had smoking-related COPD without a1-antitrypsin deficiency and had a smoking history of $>30$ pack-years (packs smoked per day x year). COPD was diagnosed based on a clinical history of exertional dyspnea and pulmonary function characterized by a partly reversible airflow obstruction. Partly reversible airflow obstruction is defined as FEV1/FVC $<70 \%$ following the inhalation of a $\beta 2$-agonist and subsequent to treatment with bronchodilators in accordance with the Global Initiative for Chronic Obstructive Lung Disease guidelines (1). Patients with a clinical history of asthma, an exacerbation or any change in their COPD therapy within 4 weeks of the study, or a history of lung cancer were excluded. Written informed consent was obtained from the patients and the Ethics Committee of Tongji University, Shanghai, China approved the study (K14-135).

Study design. Each patient performed pulmonary function tests in the following order: IOS, body plethysmography (including measurement of lung volumes) and spirometry.

Pulmonary function measurements. IOS (Masterscreen IOS, Erich Jaeger, Hoechberg, Germany) measurements were performed as described previously (15) and the actual values of Rrs at 5 and $20 \mathrm{~Hz}$ (R5 and R20, respectively), reactance at $5 \mathrm{~Hz}$ (X5) and the resonant frequency (Fres) were recorded. Forced end-expiratory flow (FEF)75 and total inspiratory resistance (Rtot) were measured in a constant volume
Table I. Patient demographics at baseline.

\begin{tabular}{lc}
\hline Characteristic & Value \\
\hline Gender & \\
Male & 157 \\
Female & 23 \\
Age, years & $61.56 \pm 9.20$ \\
Current smokers & 125 \\
Male & 109 \\
Female & 16 \\
Ex-smokers & 55 \\
Male & 48 \\
Female & 7 \\
ICS + LABA & \\
Use & 166 \\
No use & 14 \\
LANC & \\
Use & 86 \\
No use & 94 \\
Oral theophylline & \\
Use & 42 \\
No use & 83 \\
\hline
\end{tabular}

There were no patients on oral corticosteroids. ICS, inhaled corticosteroids; LABA, long acting bronchodilator, LANC, long acting anticholinergic.

Table II. Pulmonary function at baseline.

\begin{tabular}{lc}
\hline Function & Mean \pm SD \\
\hline Fres, $\mathrm{Hz}$ & $25.08 \pm 8.75$ \\
$\mathrm{R} 5, \mathrm{cmH}_{2} \mathrm{O} /(\mathrm{l} / \mathrm{s})$ & $6.06 \pm 2.60$ \\
$\mathrm{R} 20, \mathrm{cmH}_{2} \mathrm{O} /(\mathrm{l} / \mathrm{s})$ & $3.40 \pm 1.26$ \\
$\mathrm{X} 5, \mathrm{cmH}_{2} \mathrm{O} /(\mathrm{l} / \mathrm{s})$ & $-3.50 \pm 2.73$ \\
$\mathrm{FEV} 1, \mathrm{predicted}^{\circ}$ & $53.34 \pm 26.18$ \\
FEF75, predicted \% & $30.72 \pm 25.54$ \\
RV, predicted \% & $192.10 \pm 78.60$ \\
TLC, predicted \% & $117.17 \pm 25.36$ \\
Rtot, $\mathrm{kpa} / \mathrm{sec} / \mathrm{l}$ & $0.74 \pm 0.47$ \\
\hline
\end{tabular}

SD, standard deviation; FEV1, forced expiratory volume in $1 \mathrm{sec}$; FEF75, forced end-expiratory flow; RV, residual volume; TLC, total lung capacity; Rtot, total inspiratory resistance.

plethysmograph (Sensormedics Vmax 6200; SensorMedics Corporation, Yorba Linda, CA, USA), and the total lung capacity (TLC) and residual volume (RV) were then calculated from these parameters. IOS and body plethysmograph measurements were repeated three times and the mean value was used for further analysis. FEV1 was measured using the spirometry system on the Masterscreen (CareFusion, Berlin, Germany). The readings were obtained three times and the highest FEV1 was recorded. 
A

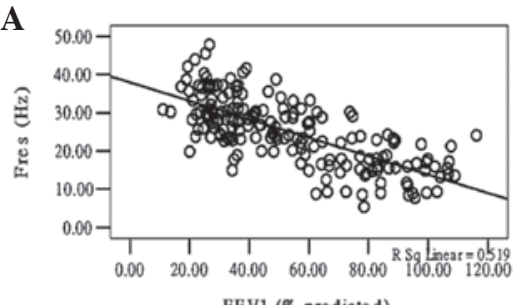

C



B

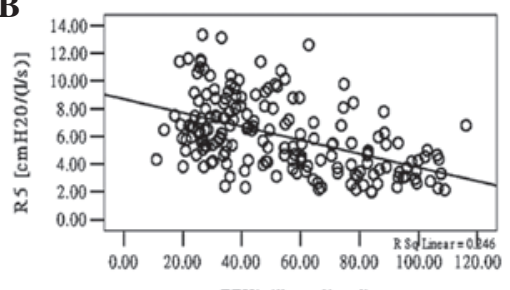

D

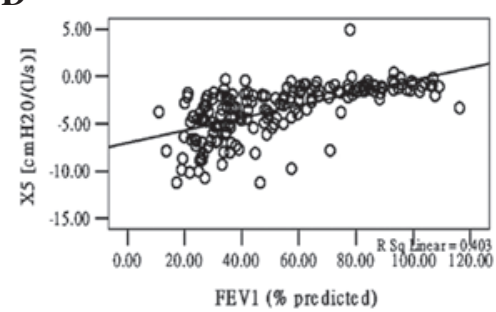

Figure 1. Corelation between IOS measurements and FEV1\% predicted at the baseline visit. (A) Fres vs. FEV1 (r=-0.721* and P=0.000), (B) R5 vs. FEV1 $\left(\mathrm{r}=-0.496^{*}\right.$ and $\left.\mathrm{P}=0.000\right),(\mathrm{C}) \mathrm{R} 20$ vs. FEV1 ( $\mathrm{r}=0.111$ and $\left.\mathrm{P}=0.138\right)$ and $(\mathrm{D}) \mathrm{X} 5$ vs. FEV1 $\left(\mathrm{r}=0.635^{*}\right.$ and $\left.\mathrm{P}=0.000\right),{ }^{*} \mathrm{P}<0.05$. IOS, impulse oscillatory system; FEV1, forced expiratory volume in $1 \mathrm{sec}$; Fres, resonant frequency.



C

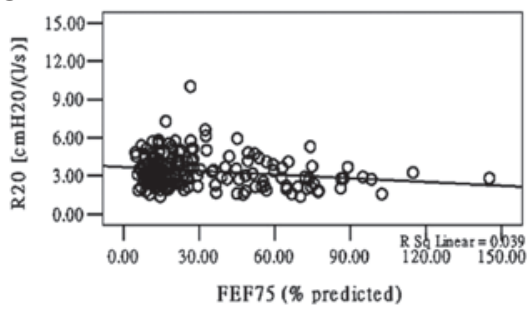

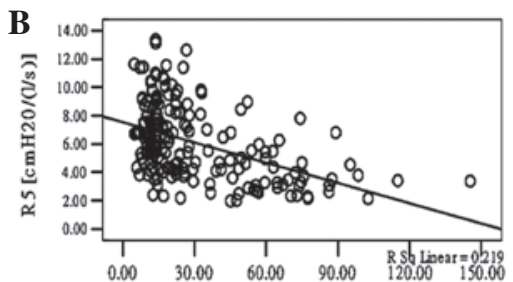

D

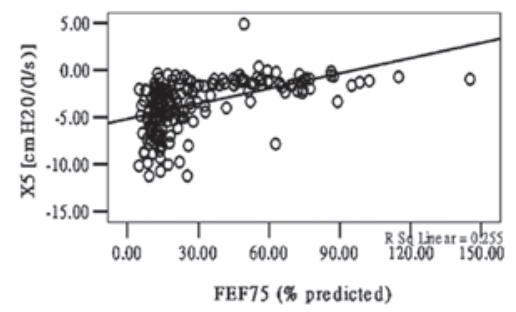

Figure 2. Correlation between IOS measurements and FEF75\% predicted at the baseline visit. (A) Fres vs. FEF7 (r=-0.629* and P=0.000, (B) R5 vs. FEF75 $\left(\mathrm{r}=-0.468^{*}\right.$ and $\left.\mathrm{P}=0.000\right),(\mathrm{C}) \mathrm{R} 20$ vs. FEF75 ( $\mathrm{r}=-0.197^{*}$ and $\left.\mathrm{P}=0.008\right)$ and $(\mathrm{D}) \mathrm{X} 5 \mathrm{vs}$. FEF75 ( $\mathrm{r}=0.505$ and $\left.\mathrm{P}=0.000\right)$, $\mathrm{P}<0.05 . \mathrm{IOS}$, impulse oscillatory system; $\mathrm{FEF}$, forced end-expiratory flow; Fres, resonant frequency..

Statistical analysis. The Kolmogorove-Smirnov test was applied to determine the normality of the data. Pearson's or Spearman's correlation tests were applied to determine the correlation between the baseline IOS and pulmonary function measurements, and the correlation between the change in FEV1 and in IOS over 1 year. The paired t-test or the Wilcoxon matched pair test was performed in order to determine the differences between the initial scores and the scores at the 1 -year follow up. $\mathrm{P}<0.05$ was considered to indicate a statistically significant difference. Statistical analyses were performed using SPSS 13.0 (SPPS Inc., Chicago, IL, USA).

\section{Results}

Baseline patient demographics and pulmonary function measurements (Tables I and II, respectively). The correlation between IOS and other pulmonary function measurements was analyzed. R5, X5 and Fres were all significantly associ- ated with FEV1 $(\mathrm{P}<0.05)$ and the correlation coefficients were $-0.496,0.635$ and -0.721 , respectively. However, R20 was not correlated with FEV1 (P>0.05; Fig. 1). R5, X5 and Fres were all associated with FEF75 $(\mathrm{P}<0.05)$ and the correlation coefficients were $-0.468,0.505$ and -0.629 , respectively. There was a lower correlation between R20 and FEF75 and the correlation coefficient was -0.197 ( $\mathrm{P}<0.05$; Fig. 2). R5, X5 and Fres were all associated with RV $(\mathrm{P}<0.05)$ and the $\mathrm{r}$ values were 0.326 , -0.485 and 0.570 , respectively. However, that was not the case with R20 (Fig. 3). R5, X5, Fres and R20 were all significantly associated with Rtot $(\mathrm{P}<0.05)$ and the correlation coefficients were $0.570,-0.691,0.632$ and 0.206 , respectively (Fig. 4).

Comparison of FEVI, RV and IOS measurements at initial tests and at 1-year follow up. In order to compare the changes in FEV1, RV and IOS measurements at 1-year follow up in the 95 patients, the changes as group statistics and changes for each individual were considered. Regarding the overall group 
A

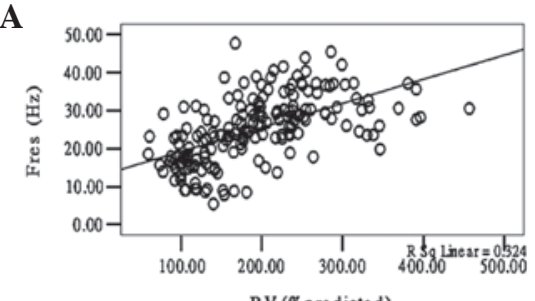

C

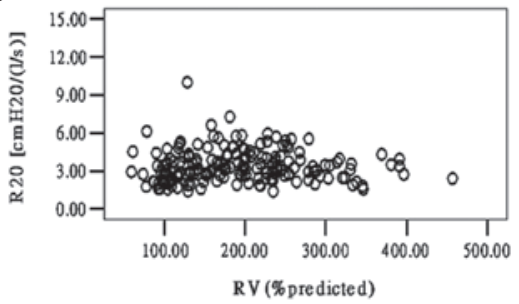

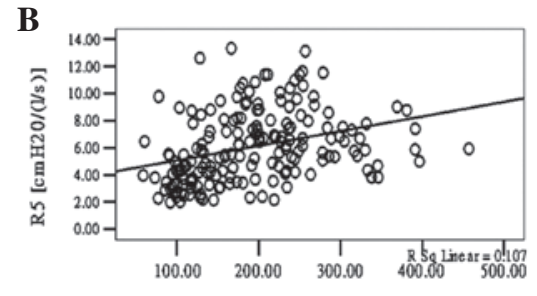

D

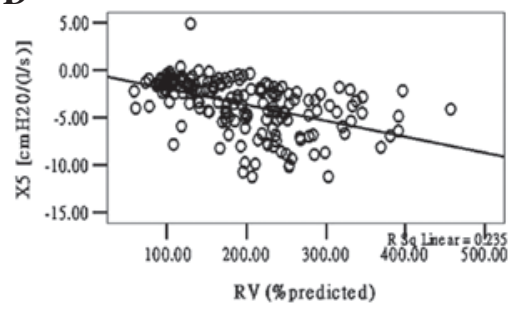

Figure 3. Correlation between IOS measurements and RV\% predicted at the baseline visit. (A) Fres vs. RV ( $r=0.570^{*}$ and $\left.P=0.000\right)$, (B) R5 vs. RV ( $r=0.326 *$ and $\mathrm{P}=0.000),(\mathrm{C}) \mathrm{R} 20$ vs. RV ( $\mathrm{r}=0.009^{*}$ and $\left.\mathrm{P}=0.903\right)$ and $(\mathrm{D}) \mathrm{X} 5$ vs. RV ( $\mathrm{r}=-0.485$ and $\left.\mathrm{P}=0.000\right)$. $\mathrm{P}<0.05$. IOS, impulse oscillometry system; RV, residual volume; Fres, resonant frequency.

A

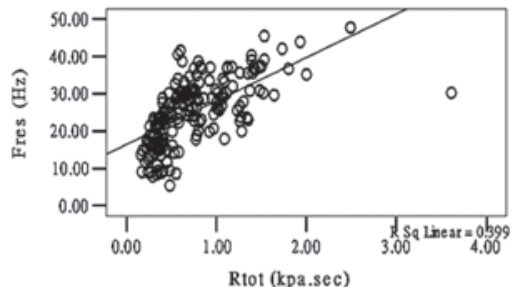

C

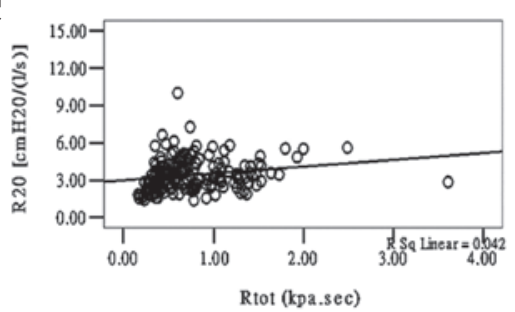

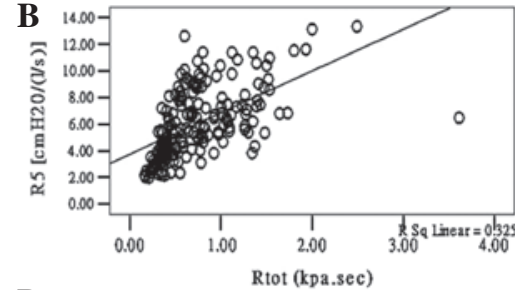

$\mathbf{D}$

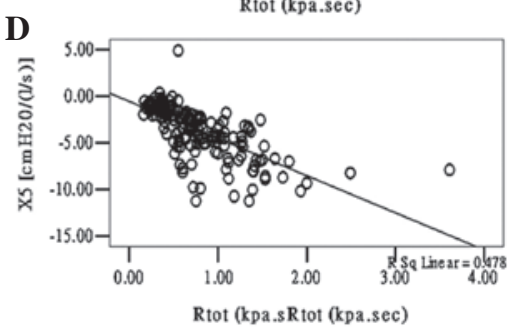

Figure 4. Correlation between IOS measurements and Rtot at the baseline visit. (A) Fres vs. Rtot ( $\mathrm{r}=0.632^{*}$ and $\left.\mathrm{P}=0.000\right)$, (B) $\mathrm{R} 5$ vs. Rtot ( $\mathrm{r}=0.570^{*}$ and $\mathrm{P}=0.000),(\mathrm{C}) \mathrm{R} 20$ vs. Rtot $\left(\mathrm{r}=0.206^{*}\right.$ and $\left.\mathrm{P}=0.006\right)$ and $(\mathrm{D}) \mathrm{X} 5$ vs. Rtot $\left(\mathrm{r}=-0.691^{*}\right.$ and $\left.\mathrm{P}=0.000\right)$, $\mathrm{P}<0.05$. IOS, impulse oscillometry system; Rtot, total inspiratory resistance; Fres, resonant frequency.
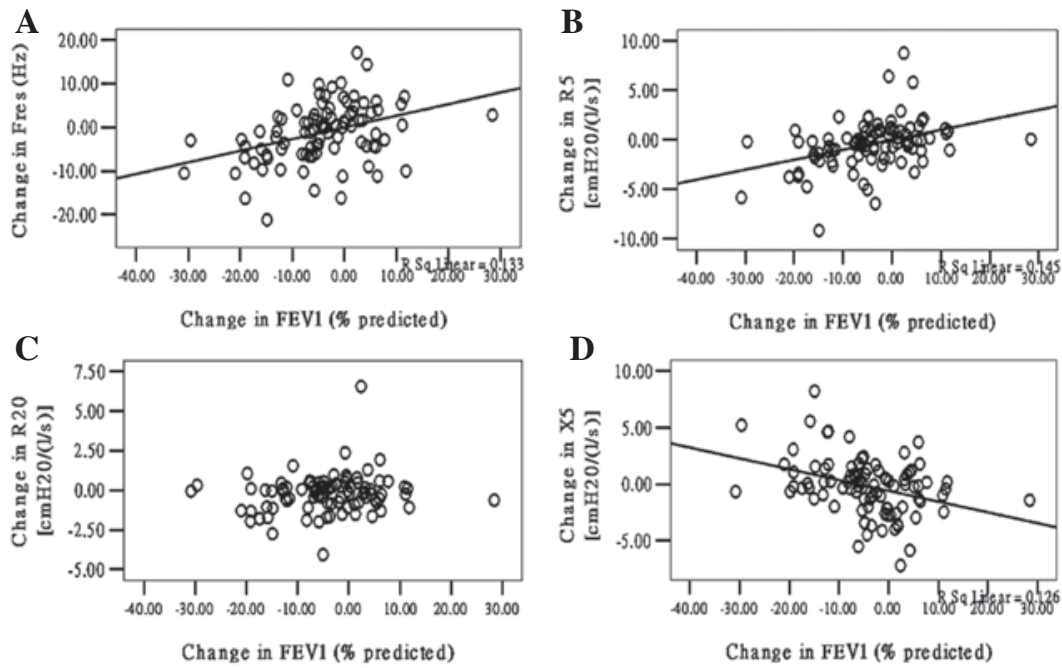

Figure 5. Correlation between the changes in IOS and FEV1 within each individual over a 1 year interval. (A) Change in Fres vs. change in FEV1 (r=-0.364" and $\mathrm{P}=0.000)$, (B) change in $\mathrm{R} 5$ vs. change in $\mathrm{FEV} 1\left(\mathrm{r}=-0.381^{*}\right.$ and $\left.\mathrm{P}=0.000\right),(\mathrm{C})$ change in $\mathrm{R} 20$ vs. change in $\mathrm{FEV} 1(\mathrm{r}=-0.138$ and $\mathrm{P}=0.183)$ and $(\mathrm{D})$ change in $\mathrm{X} 5$ vs. change in FEV1 ( $\mathrm{r}=0.355$ and $\mathrm{P}=0.450),{ }^{*} \mathrm{P}<0.05$. IOS, impulse oscillometry system; FEV1, forced expiratory volume in 1 sec; Fres, resonant frequency. 
A

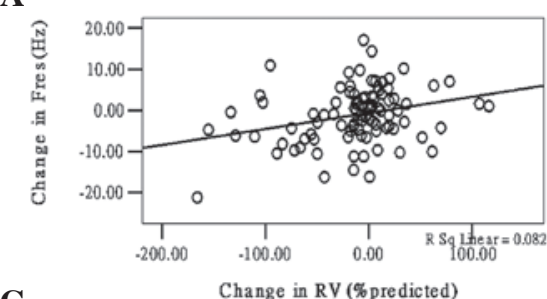

C

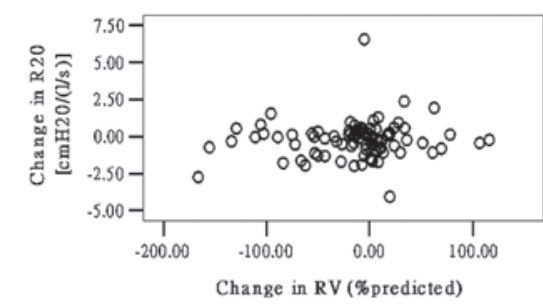

B

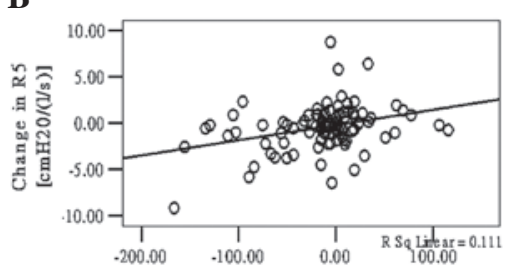

D

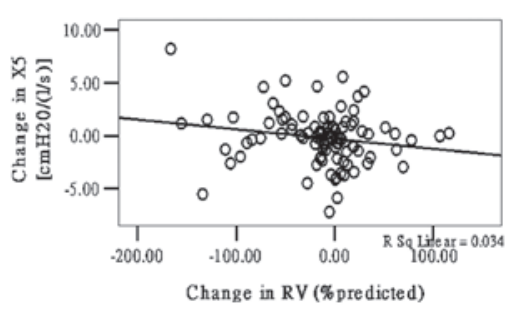

Figure 6. Correlation between the changes in IOS and RV within each individual over a 1 year interval. (A) Change in Fres vs. change in RV (r=0.287* and $\mathrm{P}=0.005)$, (B) change in R5 vs. change in RV ( $\mathrm{r}=0.318^{*}$ and $\left.\mathrm{P}=0.002\right)$, $(\mathrm{C})$ change in $\mathrm{R} 20$ vs. change in $\mathrm{RV}(\mathrm{r}=0.096$ and $\mathrm{P}=0.357)$ and $(\mathrm{D})$ change in $\mathrm{X} 5$ vs. change in $\mathrm{RV}\left(\mathrm{r}=-0.264^{*}\right.$ and $\left.\mathrm{P}=0.01\right),{ }^{*} \mathrm{P}<0.05$. IOS, impulse oscillometry system; $\mathrm{RV}$, residual volume; Fres, resonant frequency.

mean or median values, there was a statistically significant increase in the FEV1, RV and X5 after 1 year, but not in the R5, R20 and Fres (Table II).

The correlation between changes in FEV1 and IOS measurements within each individual over 1 year are shown in Fig. 5. The changes in X5, R5 and Fres were significantly correlated with the changes in FEV1; however, there was no correlation between R20 and FEV1. Similarly, the RV changes were significantly correlated with R5, X5 and Fres changes over 1 year, while there was no correlation between R20 and RV (Fig. 6).

\section{Discussion}

A total of 180 patients were selected with moderate to severe COPD, and pulmonary function and IOS tests were conducted in order to determine the correlation between these parameters and the change in the measurement values after 1 year. In total, 95 patients completed the study by returning for the 1-year follow up tests. Fres, R5 and X5 were identified to be significantly correlated with FEV1, with airflow obstruction (FEF75, Rtot) and with over inflation (RV). However, R20 had no correlation with FEV1 and RV, while it had a low degree of correlation with FEF75 and Rtot. FEV1 is a recognized indicator of airflow obstruction and FEF is used to determine the common indicators of small airflow function. Rtot, the total airway resistance, caused by airflow obstruction is one of the reasons for the increase in airway resistance. Therefore, one of the major findings of the present study is that IOS resistance in patients with airflow obstruction in COPD due to respiratory mechanics is significant. Subsequent to follow-up of the 95 patients at 1 year, a close correlation of the reactor with FEV1 was identified. After 1 year, FEV1 marginally increased when compared with the previous value. RV was marginally reduced, but X5 was increased in comparison to the previous value. The changes of X5 and FEV1 were significantly associated as were X5 and RV. R20 was not associated with FEV1 and RV. The present study was the second major study that identified X5 in the evaluation of airflow obstruction, and demonstrated that $\mathrm{X} 5$ reactance was more valuable than the other reactances.

As it is known, due to peripheral airway obstruction in patients with COPD, the respiratory compliance is reduced, the lung elastic recoil force is decreased and the elastic resistance is increased. X5 represents the peripheral reactance (capacitive and inertial reactance) and it positively correlates with FEV1 ( $r=0.635)$. At the 1 year follow-up, X5 and FEV1 were significantly increased when compared with the first visit and these two changes were significantly correlated. This result indicated that X5 can be used for the evaluation of COPD in patients with airway obstruction. Previous studies by Di Mango et al (6) and Kolsum et al (19) showed that on the first visit and at the 1 year follow-up appointment, FEV1 and X5 were significantly correlated and FEV1 was raised after one year while X5 was not. The results of the present study results were consistent with the findings of Di Mango et al and Kolsum et al. With the use of FOT methods, Di Mango et al reported that reactance measurements were better than resistance measurements for grading the severity of airflow obstruction in COPD patients (6).

The strength of the correlation between FEV1 and the reactance measurements ( $\mathrm{r}=0.635$ for $\mathrm{X} 5$ and $\mathrm{r}=-0.721$ for Fres) and between FEF75 ( $r=0.505$ for X5 and $r=-0.629$ for Fres) or Rtot ( $\mathrm{r}=-0.691$ for $\mathrm{X} 5$ and $\mathrm{r}=0.632$ for Fres) and reactance measurements indicates a moderate association between the IOS airway reactance measurements and airflow obstruction, regardless of whether measurements were assessed by FEV1 or FEF75. IOS is therefore not a replacement for FEV1, but as previously pointed out for classic FOT methods, it provides complimentary information on respiratory mechanics. IOS reactance measurements provide insights into changes in pulmonary compliance associated with the severity of airflow obstruction. By contrast, IOS reactance measurements appear to be less indicative of mechanical changes due to hyperinflation.

Xrs by capacity and inertial reactance is composed of two parts. Capacity reactance and compliance are reciprocal and more negative values reveal that the compliance is lower. 
MacLeod et al (9) found that the inertial reactance was of little clinical significance and that the Xrs changes mainly depend on the compliance of respiratory system changes. Borrill et al (15) considered that in emphysema patients, although there is a destruction of lung parenchyma, there is an increased lung compliance and that in COPD patients due to the presence of airway obstruction, the total respiratory compliance is reduced. In the present study, the stronger correlation between X5 and PFT parameters can not only be used for reflecting the respiratory compliance changes but also for the evaluation of COPD patients with airway obstruction together with FEV1.

With an increase in the Fres, the X 5 becomes more negative and indicates a decrease in compliance. The present study found that Fres and X5 were not only associated with FEV1 but were also significantly associated with RV. Van Noord et al (4) considered that the X5 decline was sensitive enough for the diagnosis of emphysema. The correlation between X5 and RV also confirmed this point. In COPD patients, the presence of emphysema led to an increase in pulmonary compliance. However, Fres and FEV1 were negatively correlated and this was due to lung hyperinflation, which resulted in the destruction of the lung parenchyma. Therefore in the present study, the correlation of IOS reactance (X5) and lung volume (RV) in COPD patients was due to lung hyperinflation caused by airflow obstruction. The significant correlation between Fres and Rtot also verified that Fres, which reflects an increase in airway resistance, was the most sensitive index.

Previous studies by Clement et al (18) have demonstrated that peripheral airway obstruction was characterized by a greater increase in the resistance at low frequencies (R5) when compared with the higher frequencies (R20). This is often referred to as the frequency dependence of resistance (20). R5 represents the total airway resistance whereas $\mathrm{R} 20$ represents proximal airway resistance. Since there is a frequency-dependent R-value, airway resistance in COPD patients depends on the R5 and not R20. Helinckx et al (8) found that R5 and Rtot were apparently correlated and that the R5 value was marginally greater than the Rtot. The present study found that R5 was significantly associated with Rtot and that R20 and Rtot were not significant, and this confirmed that R5 was more suitable than R20 to reflect airway obstruction in COPD patients. Duiverman et al (21) found that the airway resistance at low frequency distinguished patients with obstructive disease from healthy patients, which supports the findings of the present study. The current study also showed that R5, but not R20, was associated with FEV1 at the baseline visit, which adds further weight to the evidence that low frequency IOS resistance measurements can be used to assess peripheral airway obstruction in COPD patients (22). By contrast, R20 measurements appear to be unrelated to airflow obstruction in COPD patients and the value of these measurements in COPD patients are questionable.

In conclusion, it has been demonstrated that X5, R5 and Fres are IOS measurements most closely associated with more traditional measurements of pulmonary function in COPD patients. Subsequent to one year of follow-up, changes of X5 and FEV1 were identified to be closely correlated, which indicated that X5 was not only sensitive to detect airflow obstruction in COPD patients, but could provide an improved evaluation of the changes in airflow obstruction. In view of the correlation with RV, X5 was also available as an indicator to evaluate the hyperinflation in patients with COPD. Thus, the reactance measurement of X5 offers an alternative to FEV1. The ease of use of IOS and the sensitivity of this technique to measure the effects of therapeutic interventions in COPD patients may provide a basis for the increased use of this method in clinical practice.

\section{Acknowledgements}

This study was supported by the Young Foundation of Sanitary Bureau of Shanghai (grant no. 20124Y117).

\section{References}

1. Rabe KF, Hurd S, Anzueto A, et al: Global strategy for the diagnosis, management, and prevention of chronic obstructive pulmonary disease: GOLD executive summary. Am J Respir Crit Care Med 176: 532-555, 2007.

2. Cogswell JJ: Forced oscillation technique for determination of resistance to breathing in children. Arch Dis Child 48: 259-266, 1973.

3. Dubois AB, Brody AW, Lewis DH, et al: Oscillation mechanics of lungs and chest in man. J Appl Phys 8: 587-594, 1956.

4. Van Noord JA, Clément J, Van de Woestijne KP, et al: Total respiratory resistance and reactance in patients with asthma, chronic bronchitis, and emphysema. Am Rev Respir Dis 143: 922-927, 1991.

5. Zerah F, Lorino AM, Lorino H, et al: Forced oscillation technique vs spirometry to assess bronchodilatation in patients with asthma and COPD. Chest 108: 41-47, 1995.

6. Di Mango AM, Lopes AJ, Jansen JM, et al: Changes in respiratory mechanics with increasing degrees of airway obstruction in COPD: detection by forced oscillation technique. Respir Med 100: 399-410, 2006.

7. Goldman MD: Clinical application of forced oscillation. Pulm Pharmacol Ther 14: 341-350, 2001

8. Hellinckx J, Cauberghs M, De Boeck K, et al: Evaluation of impulse oscillation system: comparison with forced oscillation technique and body plethysmography. Eur Respir J 18: 564-570, 2001.

9. MacLeod D and Birch M: Respiratory input impedance measurement: forced oscillation methods. Med Biol Eng Comput 39: 505-516, 2001.

10. Dellacà RL, Santus $\mathrm{P}$, Aliverti $\mathrm{A}$, et al: Detection of expiratory flow limitation in COPD using the forced oscillation technique. Eur Respir J 23: 232-240, 2004.

11. Dellacà RL, Rotger M, Aliverti $\mathrm{A}$, et al: Noninvasive detection of expiratory flow limitation in COPD patients during nasal CPAP. Eur Respir J 27: 983-991, 2006.

12. Dellacà RL, Duffy N, Pompilio PP, et al: Expiratory flow limitation detected by forced oscillation and negative expiratory pressure. Eur Respir J 29: 363-374, 2007.

13. Houghton CM, Woodcock AA and Singh D: A comparison of lung function methods for assessing dose-response effects of salbutamol. Br J Clin Pharmacol 58: 134-141, 2004.

14. Houghton CM, Woodcock AA and Singh D: A comparison of plethysmography, spirometry and oscillometry for assessing the pulmonary effects of inhaled ipratropium bromide in healthy subjects and patients with asthma. Br J Clin Pharmacol 59: $152-159,2005$.

15. Borrill ZL, Houghton CM, Woodcock AA, et al: Measuring bronchodilation in COPD clinical trials. Br J Clin Pharmacol 59: 379-384, 2005

16. Park JW, Lee YW, Jung YH, et al: Impulse oscillometry for estimation of airway obstruction and bronchodilation in adults with mild obstructive asthma. Ann Allergy Asthma Immunol 98: 546-552, 2007.

17. Al-Mutairi SS, Sharma PN, Al-Alawi A, et al: Impulse oscillometry: an alternative modality to the conventional pulmonary function test to categorise obstructive pulmonary disorders. Clin Exp Med 7: 56-64, 2007. 
18. Clément J, Làndsér FJ and Van de Woestijne KP: Total resistance and reactance in patients with respiratory complaints with and without airways obstruction. Chest 83: 215-220, 1983.

19. Kolsum U, Borrill Z, Roy K, et al: Impulse oscillometry in COPD Identification of measurements related to airway obstruction, airway conductance and lung volumes. Respir Med 103: 136-143, 2009.

20. Lándsér FJ, Nagles J, Demedts M, et al: A new method to determine frequency characteristics of the respiratory system. J Appl Physiol 41: 101-106, 1976.
21. Duiverman EJ, Neijens HJ, Van der Snee-van Smaalen M, et al: Comparison of forced oscillometry and forced expirations for measuring dose-related responses to inhaled methacholine in asthmatic children. Bull Eur Physiopathol Respir 22: 433-436, 1986.

22. Ortiz G and Menendez R: The effects of inhaled albuterol and salmeterol in 2- to 5-year-old asthmatic children as measured by impulse oscillometry. J Asthma 39: 531-536, 2002. 